\title{
Prescribing to fit the needs of older people - the NHS Scotland Polypharmacy Guidance, 2nd edition
}

\author{
${ }^{1} \mathrm{M}$ Wilson, ${ }^{2} \mathrm{~A}$ Mair, ${ }^{3} \mathrm{~T}$ Dreischulte, ${ }^{4} \mathrm{MD}$ Witham \\ On behalf of the NHS Scotland Model of Care Polypharmacy Working Group
}

${ }^{1}$ Consultant Geriatrician, NHS Highland, ${ }^{2}$ Acting Chief Pharmaceutical Officer, Scottish Government Health Directorates, ${ }^{3}$ Lead pharmacist Research and Development, NHS Tayside, ${ }^{4}$ Clinical Reader in Ageing and Health, University of Dundee

KEYWORDS guidelines, multimorbidity, polypharmacy, prescribing

DECLARATION OF INTERESTS No conflict of interest declared.

\author{
Correspondence to MD Witham \\ Ageing and Health \\ Medical Research Institute \\ University of Dundee \\ Ninewells Hospital \\ Dundee DDI 9SY \\ UK
}

e-mailm.witham@dundee.ac.uk

\section{BACKGROUND TO THE GUIDELINES}

Medication review is a key component of comprehensive geriatric assessment, and thus forms a central part of reviewing the care of older people across a wide range of settings - for instance after a fall, during hospitalisation, in response to an episode of delirium, and as part of ongoing care in general practice. Research shows that adverse effects of medicines are a common reason for hospitalisation in older people; a large proportion of these events are preventable ${ }^{1-3}$ and a growing interest in the functional, cognitive and carer burden associated with medication has led to medication review attracting considerable attention from clinicians, healthcare managers, politicians - and also now from patients and carers.

The care of patients with multimorbidity (more than one long term condition) is now one of the greatest challenges faced by the NHS. Central to this issue is the fact that many patients will be advised to take several medicines, often where each medicine is being prescribed for a single indication. As each additional medicine increases the complexity of their care, the key healthcare aim for the clinician and individual patient remains to ensure the continuing safe and effective use of the totality of the patient's multiple medicines. There is a profusion of information for physicians and pharmacists on the indications for commencing medication, particularly medication used for secondary prevention, e.g. of cardiovascular disease. Much of this information is contained in disease-based guidelines, typically derived from evidence collected in middle-aged adults with few diseases and on few medications. There is increasing recognition that singledisease guidelines and 'one size fits all' approaches do not meet the needs of older people, particularly those with frailty and those with multimorbidity. ${ }^{4}$ In Scotland, multimorbidity has now become the rule rather than an exception, in that the majority of patients with longterm conditions have more than one condition. ${ }^{5}$ It is important to note that although the likelihood of developing a long-term condition increases with age, the majority of patients with two or more long-term conditions are actually younger than 65 years, implying that complex medication issues are not exclusively a problem in the elderly. There is also a strong association with low socioeconomic status, in that these patients tend to develop their long-term conditions 10 years earlier than those from more affluent areas.

What help is there then for prescribers and patients faced with decisions around whether to start, stop or continue medication when single disease guidelines do not apply to the complex needs of an individual patient?

In 2012, the first edition of the NHS Scotland Polypharmacy Guidance was launched to provide guidance in this area, which many non-specialists in both primary and secondary care find challenging. To coincide with the launch of the updated, second edition of this guidance, ${ }^{6}$ this short paper outlines the principles underlying the guidance, the scope and content of the guidance, and suggests how the guidance can give practical help to clinicians and patients undertaking medication reviews.

\section{WHAT IS POLYPHARMACY?}

Polypharmacy is simply 'many medicines' and the term was traditionally applied to anyone taking more than four or five medications. Such a situation is so common 
as to render this definition valueless and it is important to note that taking many medicines may be risky (because of the increased risk of drug-drug and drugdisease interactions), but it is not necessarily inappropriate if such risks are balanced by expected benefits. It is therefore crucial to discriminate between appropriate and inappropriate polypharmacy, and these are defined in the guidance as follows:

Appropriate polypharmacy is present when:

- all medicines are prescribed for the purpose of achieving specific therapeutic objectives that have been agreed with the patient

- therapeutic objectives are actually being achieved or there is a reasonable chance they will be achieved in the future

- therapy has been optimised to minimise the risk of adverse drug reactions (ADRs)

- the patient is motivated and able to take all medicines as intended.

Inappropriate polypharmacy is present when one or more medicines are prescribed that are no longer needed because:

- there is no evidence-based indication, the indication has expired or the dose is unnecessarily high

- one or more medicines fail to achieve the therapeutic objectives they are intended to achieve

- one, or the combination of several medicines, cause unacceptable ADRs, or put the patient at an unacceptably high risk of such ADRs

- the patient is not willing or able to take one or more medicines as intended.

As an example, someone with Parkinson's disease, hypothyroidism and heart failure can easily take upwards of 20 tablets each day; every one of them essential to basic functioning or symptom control. Such polypharmacy is likely to be appropriate. Conversely, a frail person with advanced dementia, living in a care home, could be on only four medications, with each one causing adverse effects without improving quality of life - a clear example of inappropriate polypharmacy.

\section{PRINCIPLES UNDERLYING THE GUIDANCE}

A number of key principles underpin the guidance as follows:

- The patient (or their nominated proxy) needs to be at the centre of the decision-making process. Appropriate treatment choices cannot be made without understanding what issues are important to the patient, what they wish to gain from taking medication (e.g. to live longer, to function better, to avoid adverse effects) and only through such an understanding can the risks and benefits of each medicine be weighed correctly.

- It is important to consider the effects of medi- cations across multiple organ systems, including those that are not its primary target (e.g. anticholinergic effects). Older patients with multimorbidity tolerate so-called 'off-target' effects poorly, and a narrow focus on a single organ system is inappropriate when considering the overall balance of benefits and risks. Avoiding harm is a key objective of medication review. It is also recognised that for some patients with multiple morbidities, treatments may need to be optimised to treat symptoms and prevent admissions to hospital, e.g. heart failure

- In patients with a limited life expectancy, attempts to prolong life or reduce event rates may be futile or unwanted. Even when life expectancy is somewhat longer, an honest dialogue with patients requires information on the absolute risks as well as the absolute benefits of therapy, which are often small.

- An overly rigid approach to selecting who to target for medication review, what medications to change, or what process to follow, is unlikely to be appropriate and will certainly fail to engage large numbers of prescribers and patients.

\section{HOW THE GUIDANCE AIMS TO HELP}

By providing a clear structure for a medication review that is centred around the individual adult. Prescribers are encouraged to see the adult as a whole and include nonpharmacological as well as pharmacological solutions. Table I shows the 7-step approach to conducting a medication review proposed by the guideline.

By focusing on knowledge and understanding. Large sections of this guideline are set aside to provide information on the evidence base around preventative medication, empowering physicians, pharmacists and patients to discuss and decide on what to take and why. The key concept here is that the more a patient differs from trial populations, the greater the weight that should be attached to other information to decide the extent to which benefits can realistically be achieved in an individual patient. Worked examples from four case scenarios are included for education. The guidance aims to provide tools, templates and options, and to provide background information to consider before the patient enters the consulting room.

By focusing on medication safety. Information and guidance is given on some of the most common medication safety issues, with particular focus on risks pertinent to frailty syndromes in older people (falls, reduced mobility, cognitive impairment and incontinence) and also on the appropriateness of selected long-term medication use of particular interest, e.g. long-term antibiotics, opioid analgesics and antipsychotic medications. 
MWilson, A Mair, T Dreischulte et al.

TABLE I The Drug Review Process

\begin{tabular}{|c|c|c|}
\hline Domain & Steps & Process \\
\hline Aims & $\begin{array}{l}\text { I. Identify objectives of } \\
\text { drug therapy }\end{array}$ & $\begin{array}{l}\text { Review diagnoses and identify therapeutic objectives with respect to } \\
\text { - Management of existing health problems } \\
\text { - } \quad \text { Prevention of future health problems }\end{array}$ \\
\hline \multirow[t]{2}{*}{ Need } & $\begin{array}{l}\text { 2. Identify essential drug } \\
\text { therapy }\end{array}$ & $\begin{array}{l}\text { Identify essential drugs (not to be stopped without specialist advice) } \\
\text { - Drugs that have essential replacement functions (e.g. thyroxine) } \\
\text { - Drugs to prevent rapid symptomatic decline (e.g. drugs for Parkinson's } \\
\text { disease, heart failure) }\end{array}$ \\
\hline & $\begin{array}{l}\text { 3. Does the patient take } \\
\text { unnecessary drug therapy? }\end{array}$ & $\begin{array}{l}\text { Identify and review the (continued) need for drugs } \\
\text { - } \quad \text { with temporary indications } \\
\text { - } \quad \text { with higher than usual maintenance doses } \\
\text { - } \quad \text { with limited benefit in general or the indication they are used for } \\
\end{array}$ \\
\hline Effectiveness & $\begin{array}{l}\text { 4. Are therapeutic } \\
\text { objectives being achieved? }\end{array}$ & $\begin{array}{l}\text { Identify the need for adding/intensifying drug therapy in order to } \\
\text { achieve therapeutic objectives } \\
\text { - to achieve symptom control } \\
\text { - to achieve biochemical/clinical targets } \\
\text { - to prevent disease progression/exacerbation }\end{array}$ \\
\hline Safety & $\begin{array}{l}\text { 5. Does the patient have } \\
\text { adverse drug reactions or } \\
\text { is at risk of adverse drug } \\
\text { reactions? }\end{array}$ & $\begin{array}{l}\text { Identify patient safety risks by checking for: } \\
\text { - } \quad \text { drug-disease interactions } \\
\text { - } \text { drug-drug interactions } \\
\text { - } \quad \text { drubustness of monitoring mechanisms for high-risk drugs and for high-risk } \\
\text { - } \quad \text { risk of accidental overdosing } \\
\text { Identify adverse drug effects by checking for: } \\
\text { - } \quad \text { specific symptoms/laboratory markers } \\
\text { - } \quad \text { cumulative adverse drug effects (see ADR table) } \\
\text { drugs that may be used to treat ADRs caused by other drugs }\end{array}$ \\
\hline $\begin{array}{l}\text { Cost- } \\
\text { effectiveness }\end{array}$ & $\begin{array}{l}\text { 6. Is drug therapy cost- } \\
\text { effective? }\end{array}$ & $\begin{array}{l}\text { Identify unnecessarily costly drug therapy by: } \\
\text { - Considering more cost-effective alternatives (but balance against } \\
\text { effectiveness, safety, convenience) }\end{array}$ \\
\hline $\begin{array}{l}\text { Adherencel } \\
\text { Patient- } \\
\text { centeredness }\end{array}$ & $\begin{array}{l}\text { 7. Is the patient willing and } \\
\text { able to take drug therapy } \\
\text { as intended? }\end{array}$ & $\begin{array}{l}\text { Identify risks to patient non-adherence by considering: } \\
\text { - Is the medicine in a form that the patient can take? } \\
\text { - Is the dosing schedule convenient? } \\
\text { - Is the patient able to take medicines as intended? } \\
\text { - Would the patient benefit from the Chronic Medication Service? } \\
\text { Ensure drug therapy changes are tailored to patient preferences by: } \\
\text { - Discuss with the patient/carer/or welfare proxy therapeutic objectives } \\
\text { and treatment priorities } \\
\text { Decide with the patient/carer/or welfare proxies what medicines have an } \\
\text { effect of sufficient magnitude to consider continuation/discontinuation }\end{array}$ \\
\hline
\end{tabular}

\section{THE REVIEW PROCESS}

Table I outlines the suggested Medication Review Process that forms the basis of the second edition of the Polypharmacy Guidance. It starts and ends with the focus on the patient, thus encouraging patient specific treatment objectives and targets. It then runs through a series of prompt questions, which encourage a systematic approach with the aim of ensuring that all medicines a patient is taking are appropriately indicated, that the medication regimen is designed to maximise benefit and to minimise risk, and that the patient is willing and able to take all medicines as intended. The result of this process may be that medicines are stopped, changed, started or indeed continued as before. The process guidance has been designed to make explicit the cognitive processes that occur in an expert medication review. Giving a clear outline of good prescribing practice should empower patients and prescribers in situations where existing guidelines do not apply, 
TABLE 2 Extract from Drug Efficacy and Applicability Table (Number Needed To Treat [NNT] Chart)

\begin{tabular}{|c|c|c|c|c|c|c|c|}
\hline $\begin{array}{l}\text { Medicine/ } \\
\text { intervention }\end{array}$ & Comparator & $\begin{array}{c}\text { Study } \\
\text { population }\end{array}$ & Outcome & $\begin{array}{c}\text { Duration } \\
\text { of trial } \\
\text { (years) }\end{array}$ & NNT & $\begin{array}{c}\text { Annualised } \\
\text { NNT }\end{array}$ & Comments \\
\hline \multicolumn{8}{|l|}{ Hypertension } \\
\hline \multirow[t]{2}{*}{$\begin{array}{l}\text { I BP control } \\
(<140 / 90 \mathrm{mmHg})\end{array}$} & \multirow[t]{2}{*}{ No treatment } & \multirow{2}{*}{$\begin{array}{l}\text { Patients with } \\
\text { hypertension } \\
\text { and age } \\
>80 y r s\end{array}$} & Total mortality & 2 & $333^{* *}$ & $666^{*}$ & \multirow{8}{*}{$\begin{array}{l}\text { "High risk is defined as } \\
\text { patients with a } \\
\text { previous history of } \\
\text { stroke } \\
\text { Cardiovascular } \\
\text { mortality and } \\
\text { morbidity includes fatal } \\
\text { MI and non-fatal MI, } \\
\text { sudden cardiac death, } \\
\text { aneurysms, congestive } \\
\text { heart failure, fatal and } \\
\text { non-fatal stroke and } \\
\text { transient ischaemic } \\
\text { attacks } \\
\text { Total mortality is death } \\
\text { from all causes } \\
\text { "NB the evidence base } \\
\text { to support the NNT } \\
\text { for impact on mortality } \\
\text { in the over } 80 \text { s is very } \\
\text { limited }\end{array}$} \\
\hline & & & $\begin{array}{l}\text { Cardiovascular } \\
\text { mortality and } \\
\text { morbidity }\end{array}$ & 2 & 35 & 70 & \\
\hline \multirow[t]{2}{*}{$\begin{array}{l}2 \mathrm{BP} \text { control } \\
(<140 / 90 \mathrm{mmHg})\end{array}$} & \multirow[t]{2}{*}{ No treatment } & \multirow{2}{*}{\begin{tabular}{|l|} 
Patients with \\
hypertension \\
High risk ${ }^{*}$ and \\
$>80$ years
\end{tabular}} & Total mortality & 2 & $333^{* * *}$ & $666^{* * 2}$ & \\
\hline & & & $\begin{array}{l}\text { Cardiovascular } \\
\text { mortality and } \\
\text { morbidity }\end{array}$ & 2 & 16 & 32 & \\
\hline \multirow[t]{2}{*}{$\begin{array}{l}3 \mathrm{BP} \text { control } \\
(<140 / 90 \mathrm{mmHg})\end{array}$} & \multirow[t]{2}{*}{ No treatment } & \multirow{2}{*}{$\begin{array}{l}\text { Patients with } \\
\text { hypertension } \\
\text { age }>60 y r s\end{array}$} & Total mortality & 4.5 & 83 & 374 & \\
\hline & & & $\begin{array}{l}\text { Cardiovascular } \\
\text { mortality and } \\
\text { morbidity }\end{array}$ & 4.5 & 23 & 104 & \\
\hline \multirow[t]{2}{*}{$\begin{array}{l}4 \mathrm{BP} \text { control } \\
(<140 / 90 \mathrm{mmHg})\end{array}$} & \multirow[t]{2}{*}{ No treatment } & \multirow{2}{*}{$\begin{array}{l}\text { Patients with } \\
\text { hypertension } \\
\text { High risk and } \\
>60 \text { years }\end{array}$} & Total mortality & 4.5 & 33 & 149 & \\
\hline & & & $\begin{array}{l}\text { Cardiovascular } \\
\text { mortality and } \\
\text { morbidity }\end{array}$ & 4.5 & 9 & 41 & \\
\hline
\end{tabular}

\section{Knowledge and understanding}

The guideline contains three main sections: background information on selected medicines, collated information on medication efficacy and applicability and a section providing more detailed guidance on managing medication safety risks.

\section{i) Background information on selected medicines}

This section runs through by British National Formulary category medications that are a common source of challenges to patients and prescribers in terms of risk and benefit. It is not intended to be exhaustive. Nor is it intended to be a list of medications that must be stopped, as it is recognised that there can be exceptions to almost any rule. The issues covered have been selected based on validated tools ${ }^{7-9}$ used to identify medication problems in older people, supplemented by clinical experience from members of the guideline development group, and thus provides a quick reference guide to the latest thinking on the key issues to address. ii) Efficacy and Applicability Table (Number Needed To Treat Chart).

This section results from work done by Medicines Information Pharmacists across Scotland who have collaborated to produce a table that summarises current evidence from randomised controlled trials on the efficacy of a range of commonly prescribed medicines. An excerpt from this section is shown in Table 2. Being aware of the Number Needed to Treat (NNT) for a therapy as well as the time period over which any worthwhile effects may accrue can help to inform rational and patient-centred therapy.

The table also includes information on the characteristics of adults included in those trials. This is important as estimating an individual patient's risk of disease in conjunction with the NNT can guide the prescriber and patient in determining the value of an intervention. This can help greatly in cases where the central issue is not whether a medication is indicated, but how much benefit it will provide and over what time period. For instance, benefits in patients with short life expectancies or in adults already on a large number of medicines are 
MWilson, A Mair, T Dreischulte et al.

more likely to be offset by an increased risk of adverse drug effects. Physicians and pharmacists should discuss these issues with the patient.

\section{iii) Medication safety}

Several areas are covered in more detail, notably anticholinergic effects of commonly prescribed medicines, antipsychotics in dementia, sedatives, and risk of falls with medications. There is also an introduction to direct-to-patient approaches such as Drugs in Dehydration Cards (which point out to patients which medications should be withheld if dehydrated.)

Selecting groups of patients on which to focus for medication reviews

Although there is no consensus on which groups of patients are most likely to benefit from medication review, the guidance suggests the following groups could usefully be prioritised:

- All patients in care homes age 50+ regardless of the number of medicines they are taking

- Patients who are aged 75 and over, on 10 or more medicines, one of which is a high risk medication and at intermediate risk of hospital admission within the next year

Other groups who may potentially benefit are:

- Patients with multimorbidity (>2 chronic conditions)

- Patients with frailty ${ }^{10}$ or frailty syndromes (e.g. falls, poor mobility)

- Patients approaching the end of their lives (e.g. those on palliative care registers)

- Patients with a dominant condition. Standard guidelines will treat each condition as an individual rather than as part of the wider context of that adult. Certain conditions 'dominate' the picture for the patient both in their impact on daily life and in their impact on prognosis. Of these conditions, dementia is perhaps the best example - dementia makes decisions on comorbid conditions more complex and the impact of dementia on prognosis and function often overrides any impact of other comorbid disease. A highly individualised approach to co-prescribing is often required in dementia, as the severity, impact and course of the illness can be so variable.

\section{Limitations}

Experience with the large-scale implementation of medication reviews continues to grow, and the guidance will inevitably evolve as such experience accrues. While medication reviews can certainly reduce high-risk prescribing and inappropriate medication use, they may also reduce the costs associated with unnecessary and unwanted prescribing. There is very little trial evidence" as to whether systematic medication review improves quality of life, reduces hospitalisation or even reduces adverse drug events; such trials are required to guide future development of guidance. The best groups of patients to target, the types of changes with the most impact, the skill mix of the team delivering reviews and the associated tools and processes all require further research and development. Finally, the quality of medication review depends on the quality of the information on benefits and harms that can be brought to bear; most medications are still not studied in older people with frailty or multimorbidity, ${ }^{12}$ and harms are usually poorly recorded and reported. ${ }^{13}$ The quality and relevance of trial data to typical end-users thus needs to improve dramatically. These observations are not an excuse for inaction, but serve to illustrate that this is a dynamic field in need of further evidence.

\section{CONCLUSION}

No guidance will ever make difficult prescribing decisions easy or straightforward. However it is hoped that the new edition of the Polypharmacy Guidance will at least provide some useful information and structure (and perhaps moral support) to those prescribers and patients who are trying to find their way through the many difficult balances between benefit and harm that occur every time a decision to prescribe or not prescribe is made. Perhaps the most important step in this is the return to a focus on the patient as a whole rather than as a jigsaw of conditions that the medication review process aims for. 


\section{REFERENCES}

I Pirmohamed M, James S, Meakin S et al. Adverse drug reactions as cause of admission to hospital: prospective analysis of 18820 patients. BMJ 2004; 329: I5-9.

2 Howard RL, Avery AJ, Slavenburg $S$ et al. Which drugs cause preventable admissions to hospital? A systematic review. Br J Clin Pharmacol 2007; 63: I36-47.

3 Beijer HJ, de Blaey Cl. Hospitalisations caused by adverse drug reactions (ADR): a meta-analysis of observational studies. Pharm World Sci 2002; 24: 46-54.

4 Hughes LD, McMurdo ME, Guthrie B. Guidelines for people not for diseases: the challenges of applying UK clinical guidelines to people with multimorbidity. Age Ageing 2013; 42: 62-9. http:// dx.doi.org/I0.1093/ageing/afs 100

5 Barnett K, Mercer SW, Norbury M et al. Epidemiology of multimorbidity and implications for health care, research, and medical education: a cross-sectional study. Lancet 2012; 380: 37-43. http://dx.doi.org// 0.1016/S0 I40-6736(I2)60240-2

6 Scottish Government Model of Care Polypharmacy Working Group. Polypharmacy Guidance. 2nd ed. Edinburgh: Scottish Government; 2015.

7 Gallagher P, Ryan C, Byrne S et al. STOPP (Screening Tool of Older Person's Prescriptions) and START (Screening Tool to Alert doctors to Right Treatment). Consensus validation. Int J Clin Pharmacol Ther 2008; 46: 72-83.
8 Dreischulte T, Grant AM, McCowan C et al. Quality and safety of medication use in primary care: consensus validation of a new set of explicit medication assessment criteria and prioritisation of topics for improvement. BMC Clin Pharmacol 2012; 12: 5. http:// dx.doi.org/ I0.1 I86//472-6904-12-5

9 Spencer R, Bell B, Avery AJ et al. Identification of an updated set of prescribing - safety indicators for GPs. Br J Gen Pract 20I4; 64 : el8I-90. http://dx.doi.org//0.3399/bjgp I4X677806

10 British Geriatrics Society. Fit for Frailty. Consensus best practice guidance for the care of older people living in community and outpatient settings. June 2014. http://www.bgs.org.uk/campaigns/fff/ fff_full.pdf (accessed 20/4/20I5).

II Patterson SM, Cadogan CA, Kerse $\mathrm{N}$ et al. Interventions to improve the appropriate use of polypharmacy for older people. Cochrane Database Syst Rev 2014; I0: CD008I65. http://dx.doi. org/I0.1002/I465I858.CD008I65.pub3

I2 Habicht DW,Witham MD, McMurdo ME.The under-representation of older people in clinical trials: barriers and potential solutions.J Nutr Health Aging 2008; 12: 194-6.

I3 Saini P, Loke YK, Gamble C et al. Selective reporting bias of harm outcomes within studies: findings from a cohort of systematic reviews. BMJ 20I4; 349: g650I. http://dx.doi.org/I0.II36/bmj. g650I 